\title{
A INTRODUÇÃO DO USO DE FERRAMENTAS DE GEOPROCESSAMENTO NO ENSINO DO PLANEJAMENTO URBANO E PROJETO URBANÍSTICO ${ }^{1}$
}

\author{
THE INTRODUTION OF USE OF GEOPROCESSING TOOLS IN TEACHING \\ URBAN PLANNING AND URBAN DESIGN
}

\author{
Naggila Taissa Silva Frota \\ Universidade Federal do Ceará (UFC) \\ naggilafrota@gmail.com
}

\begin{abstract}
Resumo
Abordaremos o papel das ferramentas de Tecnologia da Informação e Comunicação e sua influência na formação do estudante de Arquitetura e Urbanismo, destacando as mudanças de perspectiva que o uso do Geoprocessamento e de Sistemas de Informação Geográficas (SIGs) traz para a profissão. As vantagens na utilização de informações espaciais georreferenciadas no processo de planejamento urbano decorre principalmente da habilidade dos SIGs de manipular dados de diferentes formatos oriundos de diversas fontes o que facilita análises espaciais complexas. Nosso objetivo é descrever o que está sendo desenvolvido no curso de graduação em Arquitetura e Urbanismo da Universidade Federal do Ceará a partir do estudo de caso das disciplinas do eixo de Projeto Urbano. O SIG auxilia na etapa de diagnóstico da área de estudo aplicando procedimentos de captura e importação de dados brutos, edição, armazenamento e estruturação de banco de dados geográficos, consulta e análise relacionada ao tema principal da disciplina e apresentação dos resultados obtidos. Constata-se o maior entendimento por parte dos alunos quanto as vantagens do uso do SIG, bem como as implicações dessa ferramenta no processo de planejamento urbano, além de estarem mais preparados para lidar com a realidade da escassez de dados.
\end{abstract}

Palavras-chave: Planejamento Urbano. Projeto Urbanístico. Sistema de Informação Geográfica. Geoprocessamento.

\begin{abstract}
We will discuss the role of information and communication technology and its influence on the formation of the student of architecture and urbanism, highlighting the changes in perspective that the use of Geoprocessing and Geographic Information Systems (GIS) brings to the profession. The advantages in using spatial geo-referenced information in the urban planning process stems mainly from the ability of GIS to manipulate data of different formats from various sources which facilitates complex spatial analysis. Our goal is to describe what is being developed in the undergraduate program in architecture and Urbanism from the Federal University of Ceará from a case study of the disciplines of the axis of urban project. The SIG helps in the diagnosis of the study area by applying procedures for capturing and importing of raw data, editing, storing and structuring of geographical database, query, and analysis related to the main theme of the discipline and presentation of the results obtained. Note the greater understanding by the students as the advantages of the use of GIS, as well as the implications of this tool in the process of urban planning, in addition to being more prepared to deal with the reality of the scarcity of data.
\end{abstract}

Keywords: Urban Planning. Urban Project. Geographic Information System. Geoprocessing.

\footnotetext{
${ }^{1}$ FROTA, N. Introdução do uso de ferramentas de geoprocessamento no ensino do Planejamento Urbano e Projeto Urbanístico. In: ENCONTRO BRASILEIRO DE TECNOLOGIA DE INFORMAÇÃO E COMUNICAÇÃO NA CONSTRUÇÃO, 7. 2015, Recife. Anais... Porto Alegre: ANTAC, 2015.
} 


\section{标}

\section{TIC2015}

\section{INTRODUÇÃO}

O modelo organizacional da sociedade do século XXI está atrelado ao desenvolvimento tecnológico, principalmente após a popularização da internet, fato que modificou substancialmente a quantidade, a qualidade e a velocidade de transmissão de informações. Combinado a esse fenômeno, a revolução da Tecnologia da Informação e Comunicação (TIC), na década de 70, deu origem à Sociedade da Informação e do Conhecimento que é caracterizada:

[...] pela importância crescente dos recursos tecnológicos e pelo avanço das [...] TICs com impacto nas relações sociais, empresariais e nas instituições [...] e cogita uma capacidade constante de inovação. (PEREIRA; SILVA, 2009, p. 152)

No âmbito do planejamento urbano, a evolução tecnológica permitiu produzir dados mais precisos e confiáveis sobre o território, o sensoriamento remoto, aerofotogrametria e o Sistema de Posicionamento Global são técnicas que captam e retratam as deformações da superfície terrestre com relativa fidelidade. O ponto em comum das ferramentas citadas é o uso de um sistema de coordenadas absoluto que garante a precisão dos dados obtidos de acordo com a realidade observada.

A fim de manipular dados geográficos e relacioná-los com atributos alfanuméricos, surge o Geoprocessamento como um campo do conhecimento que se utiliza de um Sistema de Informação Geográfica (SIG) capaz de montar um banco de dados georreferenciado e automatizar a confecção de produtos cartográficos.

Saboya (2000) defende que dentro do processo de planejamento urbano existem três etapas básicas que exigem análises espaciais, portanto, que são passíveis da utilização de SIG, são elas: a definição do problema, a avaliação e seleção da melhor alternativa e o monitoramento. Ele salienta que a habilidade dos SIGs de manipular dados de diferentes formatos oriundos de diversas fontes facilita análises espaciais complexas, o que significa que o SIG diminui a complexidade da realidade estudada através de sobreposições de informações espaciais.

Complementarmente, a visão de Câmara e Davis (2000) explicita que o Brasil possui enorme carência de informações que auxiliem nas decisões sobre problemas urbanos, e acrescentam que o Geoprocessamento, baseado em tecnologias de baixo custo e de conhecimento local, possui potencial para reverter essa realidade.

Freitas, Gomes e Borges (2013) confirmam o cenário de desinformação urbanística através de incoerências entre as intenções presentes na legislação urbana e o desenvolvimento da cidade. A partir de um estudo de caso, eles relacionam a ineficiência do planejamento urbano com a escassez de uma base de informações que retrate com fidelidade o ambiente construído. Vale ressaltar que:

Tendo em vista que a maior parte das decisões tomadas pelo planejamento e gestão urbana possui um componente espacial importante, o mapeamento das informações torna-se fundamental, pois permite uma maior cognição por parte do gestor urbano (FREITAS; GOMES; BORGES, 2013, p. 36)

Portanto, é evidente que a prática do planejamento urbano exige conhecimento preciso das condições do território e, atrelado a isso, o SIG se mostra capaz de espacializar informações e, assim, auxiliar na compreensão de processos urbanos. 
Portanto, é imprescindível direcionar a formação dos futuros planejadores urbanos no sentido de ampliar sua consciência quanto a importância do geoprocessamento e do SIG e torná-los aptos a se apropriar dessa modalidade de TIC.

O objetivo principal deste trabalho é descrever o que vem sendo desenvolvido no curso de graduação em Arquitetura e Urbanismo no sentido de introduzir novas ferramentas de TIC, além de averiguar a receptividade do corpo discente diante do incremento do geoprocessamento nas disciplinas de planejamento urbano e projeto urbanístico. De maneira geral, pretende-se compreender como a utilização do SIG pode influenciar os futuros planejadores urbanos a construir um arcabouço de informações georreferenciadas úteis para o país.

O método utilizado nesse trabalho baseia-se no estudo de caso de 3 disciplinas do eixo de Projeto Urbano durante os semestres de 2014.2 e 2015.1, correspondendo ao total de 6 turmas. Estabeleceu-se uma análise comparativa a fim de mensurar os produtos elaborados, o perfil da turma, o nível de manuseio do software e a relação entre o número de facilitadores e o número de alunos. Estas disciplinas são organizadas em 3 etapas, a primeira voltada para estudo teórico referente ao tema principal, a segunda com foco no diagnóstico da área de estudo e a terceira com caráter propositivo. O SIG está presente fundamentalmente na segunda etapa e se concentra em aplicar procedimentos de captura e importação de dados brutos, edição, armazenamento e estruturação de banco de dados geográficos, consulta e análise relacionada ao tema principal da disciplina e apresentação dos resultados obtidos.

Portanto, nossos resultados são parciais e referentes a uma experiência didática que descreve interações entre os estudantes e o SIG. Observa-se a crescente autonomia dos alunos na montagem e consulta de um banco de dados simples com variáveis desejadas para o estudo proposto na disciplina. A maior parte das turmas produziu novas informações a partir da manipulação de dados primários obtidos em órgãos públicos. Constata-se o maior entendimento por parte dos alunos quanto as vantagens do uso do SIG e suas implicações no processo de planejamento urbano.

Com relação as limitações encontradas, Saboya (2000) salienta que o SIG não tem capacidade de formular ações preditivas, ou seja, o SIG não delibera ações modificadoras do espaço urbano. Nesse sentido, avançamos no uso da tecnologia Building Information Modeling (BIM) e City Information Modeling (CIM) vinculada a outras disciplinas, e assim conseguimos superar esta deficiência do SIG.

\section{FERRAMENTAS GIS NO ENSINO SUPERIOR}

\subsection{O Projeto Político Pedagógico}

O Projeto Político Pedagógico (PPP) de uma instituição de ensino superior deve refletir a identidade e os direcionamentos de cada unidade de ensino, de forma a guiar as ações didáticas, científicas e culturais que influenciam a formação acadêmica e profissional do corpo discente.

O atual PPP do Curso de Arquitetura e Urbanismo da Universidade Federal do Ceará procura refletir sobre o ensino e a prática da arquitetura e do urbanismo nos tempos atuais levando em consideração as transformações sociais, as especificidades da sociedade brasileira e os rumos da tecnologia.

O curso está organizado em 6 diferentes eixos curriculares (percepção e representação; $\square$ teoria e história da arquitetura e do urbanismo; $\square$ projeto arquitetônico; projeto urbano; tecnologia e inter-áreas) e está dividido temporalmente em três ciclos 
(fundamentação, profissionalização e conclusão).

Daremos ênfase nesse trabalho no que concerne as disciplinas do eixo de Projeto Urbano que oferece aos estudantes noções básicas da relação entre o espaço físico e o espaço social. Neste eixo busca-se contribuir para a formação crítica e criativa do aluno de modo a ampliar sua percepção acerca da análise da área de estudo e do ambiente construído. Aborda desde aglomerações urbanas em escala reduzida até grandes intervenções em contextos complexos de degradação.

Em menor grau, tratamos o ciclo de fundamentação que se concentra nos quatro semestres iniciais do curso e é caracterizado com uma maior carga horária de disciplinas, já que o aluno recém-ingresso na universidade nunca teve contato com o conteúdo mínimo para o desenvolvimento de projetos arquitetônicos e urbanísticos. Deste ciclo abordaremos a disciplina de Planejamento Urbano e Regional 2 (PUR2) lecionado no $4^{\circ}$ semestre.

O ciclo de profissionalização, também composto por quatro semestres, engloba assuntos voltados ao que denominamos atividades-fim do profissional arquiteto-urbanista. As disciplinas de Projeto Urbanístico 1 (PU1) e Projeto Urbanístico 3 (PU3), ministradas respectivamente no $5^{\circ}$ e $7^{\circ}$ semestres, são componentes do estudo de caso apresentado.

Na Figura 1 é possível observar com maior clareza a distribuição dos eixos curriculares, dos ciclos e das disciplinas ao longo do curso com ênfase nas disciplinas de projeto urbanístico.

Figura 1 - Resumo da grade curricular do curso de Arquitetura e Urbanismo - UFC

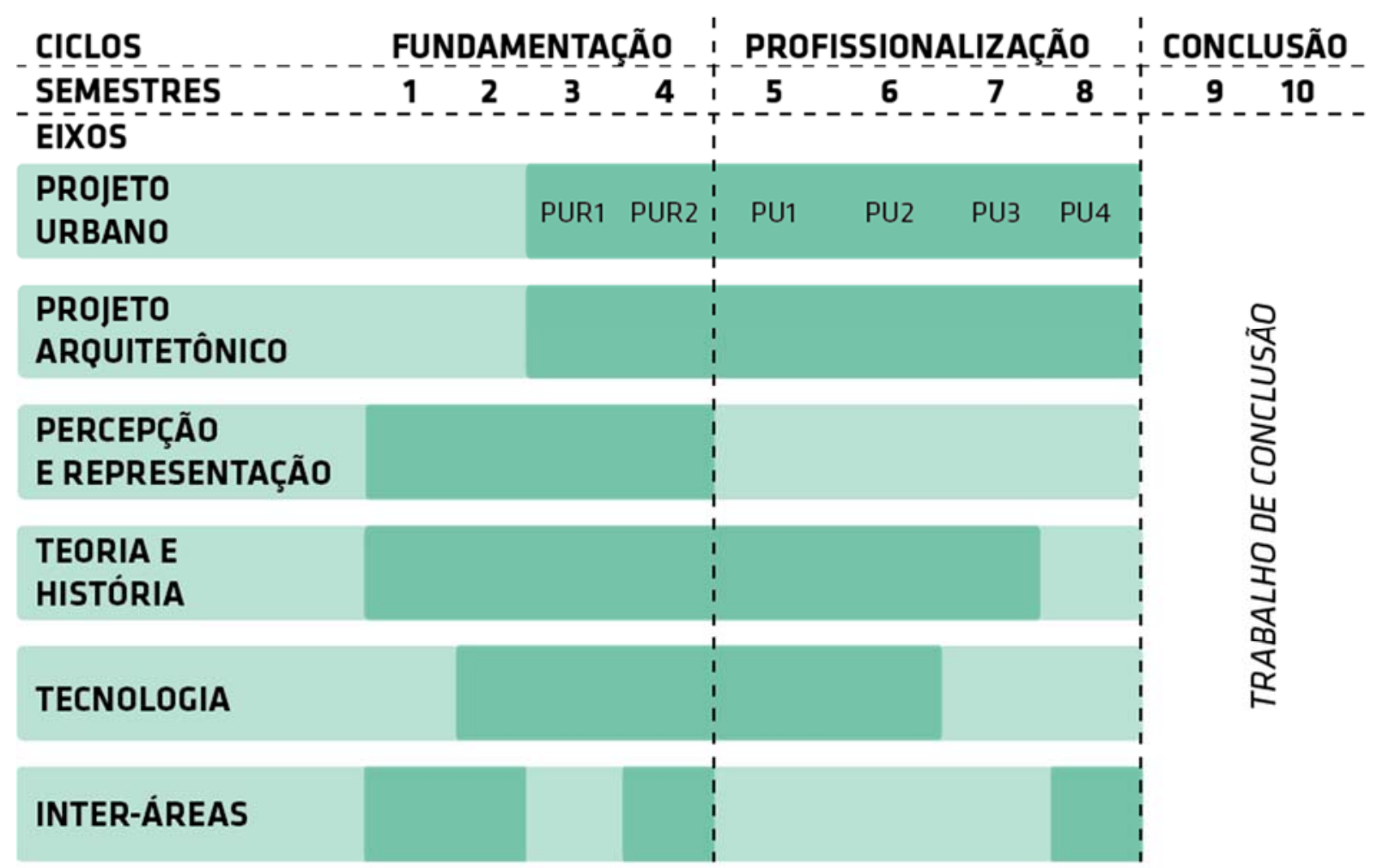

Periodo de desenvolvimento do eixo curricular durante o curso 


\section{$2=$}

\subsection{Estudo de Caso}

De acordo com o PPP, propõe-se a utilização de ferramentas provenientes da TIC para ampliar a cognição e o domínio dos estudantes acerca do projeto arquitetônico e urbanístico. O contato dos alunos, desde o início do curso, com o BIM ou o SIG é definidor na sua formação, pois este é o maior momento de experimentação na trajetória acadêmica, já que ainda não foi definida uma rotina de trabalho pelos estudantes. A partir desse ponto é mais provável que o aluno desenvolva maior inclinação para aprofundar suas habilidades diante dessas ferramentas.

As as disciplinas abordadas neste trabalho seguem uma sequência lógica semelhante que começa com a construção de repertório e posteriormente dá espaço à proposição de soluções. Inicialmente as disciplinas têm maior foco na carga teórica com o intuito de preparar os alunos criticamente e intelectualmente para a modificação do espaço urbano. No segundo momento é imprescindível o conhecimento da área de estudo para iniciar o processo de aproximação e apropriação. Ao fim a realidade diagnosticada deve ser alterada de acordo com as técnicas apreendidas.

Essas disciplinas buscam a valorização do geoprocessamento como uma técnica responsável pela ampliação do alcance das decisões urbanísticas. Para avaliar comparativamente as turmas, elencamos alguns aspectos que serão analisados no universo de dois semestres, ou seja, seis turmas. São eles:

- Histórico e perfil da turma;

- Número de facilitadores versus número de alunos

- Complexidade da utilização;

- Qualidade do produto final.

O histórico e perfil da turma consiste numa avaliação do prévio conhecimento sobre SIG seja através de disciplinas anteriores ou de atividades extracurriculares. O número de facilitadores versus o número de alunos influencia sobremaneira no desempenho da turma, sendo o ideal o número de 10 alunos para 1 facilitador. A complexidade de utilização da ferramenta aponta numa escala de intensidade se ocorreu uso em alto, médio ou baixo grau, para isso observa-se as diferentes operações realizadas pelos usuários. Soma-se a isso o fato dos alunos terem manipulado, ou não, dados secundários ou se houve a produção de dados primários. A qualidade do produto final vai mensurar o resultado obtido pelos alunos na etapa de Diagnóstico quanto a sua capacidade de transmitir as conclusões observadas pelo grupo no que concerne a sua organização gráfica e coesão de ideias. Todos os critérios obedeceram a mesma escala de intensidade para facilitar a comparação, que consta dos níveis alto, médio e baixo. Na Figura 2 é possível ver um resumo desses critérios.

Temos 3 disciplinas do eixo de Projeto Urbano que antecedem PUR2, portanto, os alunos do $4^{\circ}$ semestre já têm uma bagagem de conhecimento razoavelmente organizada. A ementa de PUR2 traz como instruções o estudo do município e do Plano Diretor, o estudo do instrumento de zoneamento conectado à política urbana e o fenômeno da metropolização.

Em PUR2, os alunos são mais abertos a incorporar técnicas de geoprocessamento, por ainda não terem inserido na sua rotina de trabalho nenhum programa específico que auxilie nas disciplinas de urbanismo. O histórico dos alunos que compunham a turma de 2014.2 era de apenas uma breve introdução em geoprocessamento, o que significa dizer que eles sabem do que se trata, apreendem superficialmente sua importância, mas não utilizaram efetivamente.

Na primeira fase da disciplina foi feito um exercício individual que abordava a análise dos 
problemas urbanos do bairro onde cada aluno morava. Este trabalho serviu como um teste inicial para avaliar o desenvolvimento da turma até aquele momento do curso. Portanto, eles não tiveram auxílio induzido pelo corpo docente quanto ao uso de softwares. $O$ que se percebeu foi um desempenho fraco e incipiente. A grande maioria utilizou imagens do Google Maps de baixa resolução para compor o mapeamento exigido.

Figura 2 - Resumo dos critérios de análise das disciplinas

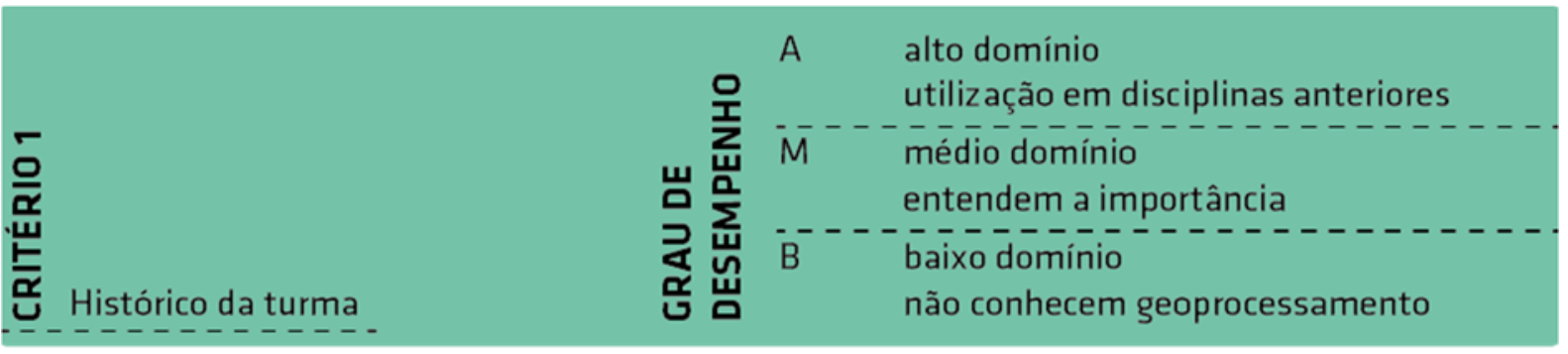

\begin{tabular}{|c|c|c|}
\hline 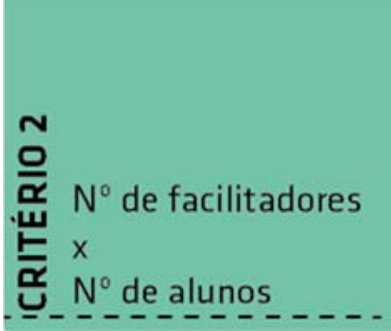 & 옴 & $\begin{array}{l}\text { A lta proporção } \\
\text { um facilitador para } 10 \text { alunos } \\
\text { média proporção } \\
\text { um facilitador para } 20 \text { alunos } \\
\text { baixa proporção } \\
\text { um facilitador para } 40 \text { alunos }\end{array}$ \\
\hline
\end{tabular}

\begin{tabular}{|c|c|c|c|}
\hline 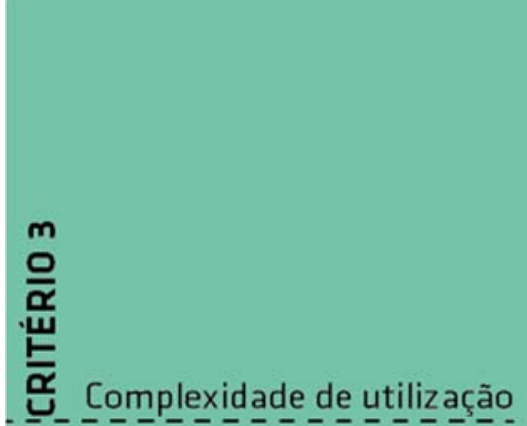 & 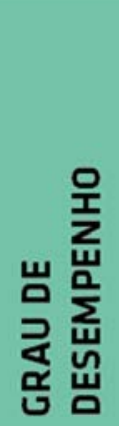 & $\begin{array}{l}A \\
\bar{M}-\cdots \\
\bar{B}^{-\cdots}-\cdot-\end{array}$ & $\begin{array}{l}\text { alta complexidade } \\
\text { cruzamento de dados } \\
\text { geração de dados primários } \\
\text { média complexidade } \\
\text { extração de dados a partir de geometrias } \\
\text { alto número de operações } \\
\text { baixa complexidade } \\
\text { visualização dos dados } \\
\text { utilização de dados de terceiros }\end{array}$ \\
\hline
\end{tabular}

\begin{tabular}{|c|c|c|c|}
\hline $\begin{array}{l}\stackrel{\text { o }}{\alpha} \\
\text { 㞾 } \\
\frac{\alpha}{\alpha} \text { Qualidade do produto }\end{array}$ & 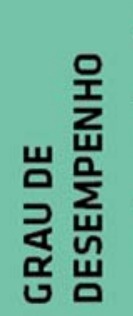 & $\begin{array}{l}A \\
\bar{M} \\
\bar{B}\end{array}$ & $\begin{array}{l}\text { alta comunicação visual } \\
\text { alta coesão das idéias } \\
\text { média comunicação visual } \\
\text { média coesão das idéias } \\
\text { baixa comunicação visual } \\
\text { baixa coesão das idéias }\end{array}$ \\
\hline
\end{tabular}

Fonte: Elaborado pela autora, 2015

$\mathrm{Na}$ etapa seguinte, Diagnóstico Temático, foram reservadas duas aulas para ensinar os princípios básicos de geoprocessamento e demonstrar como eles poderiam manipular o software a fim de encontrar as informações solicitadas no roteiro do trabalho. Não pôde ser dedicado maior tempo, pois a turma tinha cerca 30 alunos e apenas um facilitador, essa condição não possibilidade $\mathrm{o}$ atendimento individual. Por se tratar de um Diagnóstico Temático, diversas equipes não sentiram necessidade de utilizar o geoprocessamento, outras utilizaram uma base de dados disponibilizada em disciplinas anteriores que continha dados do Instituto Brasileiro de Geografia e Estatística em formato kmz, como coleta de lixo, 
abastecimento de água e rede de esgoto. Observou-se a utilização do software de geoprocessamento de forma amadora, apenas para visualização dos dados. O resultado final dos trabalhos foi relativamente bom, porém este mérito não está vinculado a utilização do geoprocessamento.

No semestre seguinte, 2015.1, o histórico da turma alegava maior contato com softwares de geoprocessamento nas disciplinas anteriores, portanto infere-se que ocorreu uma aproximação mais significativa entre os alunos e os dados, sendo esses mais confiantes e mais pré-dispostos a utilizar a ferramenta. A proporção entre o número de facilitadores e o número de alunos foi a mesma do semestre anterior.

Assim como no semestre anterior, em 2015.1 também foi feito um exercício individual, este porém se focava no mesmo objeto de estudo das etapas subsequentes, o Centro de Fortaleza. Essa estratégia trouxe ao Diagnóstico Temático maior qualidade e maior complexidade das informações expostas. Por terem estudado no primeiro trabalho a mesma área, no segundo já havia material suficiente produzido, o que facilitou a coleta de dados e deu mais tempo para a análise e conclusões.

O resultado desse trabalho, comparado ao semestre anterior, foi melhor, pois agora os alunos traziam informações mais completas e coesas, observando-se maior unidade de linguagem formal e com um cuidado especial em relação a fonte de obtenção dos dados.

Já a disciplina de PU1 traz como ementa a elaboração de um projeto urbanístico a partir da identificação de problemas e potencialidades de modo a conceber propostas de transformação de uma realidade urbana na escala da unidade de vizinhança e sob a perspectiva do desenho universal, do meio ambiente e da sustentabilidade.

Em PU1 a proposta foi trabalhar um assentamento informal nos dois semestres. O histórico da turma de 2014.2 era semelhante ao da turma de PUR2 do mesmo semestre, ou seja, tiveram um breve contato com softwares de geoprocessamento. $O$ número de alunos era reduzido, somando o total de 18 alunos acompanhados duas professoras e uma monitora.

O primeiro trabalho era voltado ao estudo de outras intervenções em favelas para ampliar o leque de opções quando fosse o momento de proposição. Na segunda etapa os alunos receberam o diagnóstico da área já completo e organizado, proveniente de outros estudos desenvolvidos pelo corpo docente responsável pela disciplina. Portanto, esta etapa se concentrou na coleta de dados relativos a uma área específica medindo cerca de 5 hectares.

Diferente de PUR2, em PU1 os alunos eram condicionados a utilizar o software de geoprocessamento. O exercício exigia a obtenção das áreas das edificações, densidade populacional por quadras, uso e ocupação do solo por lotes e hierarquia do sistema viário. Foi utilizada a base de dados cadastral de Fortaleza em formato original CAD gerada a partir de aerofotogrametria cedida pela Prefeitura. A proposta metodológica era elaborar toda a informação em sala de aula, portanto, observa-se alta complexidade no manuseio do software. O resultado dessa etapa foi bastante satisfatório, algumas equipes incluíram informações extras como a análise das edificações com banheiro.

A turma de PU1 do semestre 2015.1 é a mesma turma de PUR2 do semestre 2014.2 já que são disciplinas subsequentes. O primeiro trabalho foi semelhante ao do semestre anterior, já o segundo trabalho, o diagnóstico, foi em outro formato, pois a área de estudo não tinha nenhum material pronto para repassar aos alunos. Portanto, os alunos tiveram que produzir o banco de dados que daria origem ao diagnóstico temático. Nesse sentido, eles adquiriram muitas informações de órgãos públicos e sítios da internet e fizeram o mesmo exercício de trabalhar uma área com cerca de 5 hectares e extrair informações específicas.

Esta turma tinha auxílio da professora e de mais duas monitoras, cerca de um terço das 
horas-aula foi dedicado exclusivamente ao atendimento de dúvidas geradas pelo software. $O$ resultado final foi satisfatório do ponto de vista dos dados alcançados e da qualidade gráfica, porém observou-se que os alunos não finalizaram o trabalho diretamente no software, ou seja, a geração das pranchas finais prontas para impressão foram feitas em outros aplicativos de edição vetorial.

Por se tratar de uma disciplina mais próxima do fim do curso, o PU3 concentra alunos de perfil heterogêneo, inclusive muitos acabaram de retornar do intercâmbio no exterior. No semestre de 2014.2, além da turma ser composta por 40 alunos e ser assistida por apenas um facilitador, poucos sabiam do que se tratava geoprocessamento e praticamente ninguém teve contato prévio com o software. Esse conjunto de fatores impossibilitou a adoção da ferramenta, pois o acompanhamento das dúvidas se torna difícil e atrapalha o andamento da disciplina. Ainda foi feito um esforço no sentido de apresentar o software através de uma aula expositiva e foram disponibilizados tutoriais, porém a grande maioria da turma não aderiu ao geoprocessamento.

Nesse cenário o critério Complexidade de Utilização do Software não se aplica, por esse motivo consideramos a nível mais baixo no critério Qualidade do Produto Final.

Já no semestre 2015.1 a turma tinha 17 alunos e a logística foi mais simples. Trabalhamos a composição de um Sistema de Espaços Livres baseados na metodologia proposta por Raquel Tardin. Não demos ênfase ao geoprocessamento na primeira etapa da disciplina, visto que os alunos já possuem maior desenvoltura em aquisição e manipulação de dados. $\mathrm{Na}$ segunda etapa era necessário fazer o mapeamento e a hierarquização dos espaços livres presentes na área de estudo, portanto, foi preciso atribuir critérios e pontuações a fim de observar quais os espaços livres de maior interesse. Assim, propusemos a ferramenta como um auxílio, não sendo obrigatória sua utilização. Surgiu do próprio corpo discente a solicitação de uma aula para explanação das ferramentas introdutórias direcionadas para a montagem do banco de dados do PU3. A adesão a ferramenta foi completa, considera-se que os alunos desenvolveram operações complexas ao nutrir o banco de dados com informações geradas por eles próprios e fazer operações matemáticas para produzir uma classificação. O resultado final foi satisfatório do ponto de vista da quantidade e qualidade dos dados produzidos.

Com o objetivo de resumir os dados acima foi gerada a Figura 3 abaixo:

Figura 3 - Síntese das notas por turma

\begin{tabular}{|c|c|c|c|c|c|c|}
\hline \multirow{4}{*}{$\frac{N}{\sim}$} & PIR? & M & $M$ & $M$ & $M$ & $M$ \\
\hline & DII & M & i & (1) & 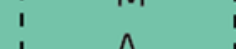 & 1 \\
\hline & PU1 & M & A & A & A & $A+$ \\
\hline & PU3 & i & B & - & B & B \\
\hline & & i & i & i & i & i \\
\hline \multirow{3}{*}{ 둠 } & PUR2 & i & i & A & : & $\mathrm{A}+$ \\
\hline & PU1 & ! & i & A & $M$ & $A+$ \\
\hline & & B & M & A & A & A- \\
\hline
\end{tabular}

Fonte: Elaborado pela autora, 2015

De maneira geral, ao fim de cada etapa, buscamos o feedback por parte dos alunos perguntando sobre os diversos aspectos da disciplina, numa espécie de avaliação, e dentro disso os prós e os contras da utilização da ferramenta. De maneira geral, o que se observa é um maior interesse por parte dos alunos em aprofundar o conhecimento neste tema.

Devemos esta repercussão ao esforço de outros docentes, que nos anos de 2008 e 2010 
integraram o quadro de professores efetivos e trouxeram maiores conhecimentos sobre TICs. Um indicador confiável do grau de adesão às novas ferramentas é o número de Trabalhos Finais de Graduação que se valem de ferramentas BIM e SIG nas suas metodologias.

\section{CONCLUSÕES}

A experimentação e os resultados expostos nesse trabalho demonstram o movimento dos estudantes de arquitetura e urbanismo na direção da incorporação de ferramentas tecnológicas nas suas rotinas de trabalho. Fica claro que quanto mais cedo é inserido no curso esse tipo de instrumento, mais provável é a adesão dos alunos. Soma-se a isso o fato de que os trabalhos ficam mais completos e a percepção dos estudantes sobre o espaço urbano é ampliada.

Levando em consideração que o Brasil não tem um vasto banco de dados sobre o espaço urbano, abordar conhecimentos de geoprocessamento faz com que os alunos desenvolvam maior autonomia na aquisição e geração de dados. Com essas iniciativas pretendemos despertar no corpo discente o interesse pela TIC demonstrando as vantagens do SIG e almejamos preparar profissionais mais qualificados para tratar com a realidade da desinformação.

Dentro da atual conjuntura evolutiva, compreende-se a TIC como um desdobramento da relação entre o usuário e a tecnologia, de forma a promover a maior interação entre ambos e facilitar a obtenção, geração e disponibilização de informações. Pereira e Silva (2009) defendem que a TIC pode contribuir para o desenvolvimento local das cidades por meio do aperfeiçoamento dos processos de tomada de decisão e consequente melhoria dos serviços públicos oferecidos aos cidadãos.

Corroborando com a visão acima, a recente publicação das Nações Unidas intitulada The role of ICT in the proposed urban sustainable development goal and the new urban agenda traz uma discussão ampla sobre as possibilidades de inserção da TIC na construção de cidades mais sustentáveis. O Objetivo 11 - Make cities and human settlements inclusive, safe, resilient and sustainable - seguido pela meta de maior interação entre cidadãos e governança, demonstra um campo de trabalho eficiente para a TIC. Sem dúvida, o maior desafio da implementação de TICs voltadas ao desenvolvimento urbano está na aproximação entre os cidadãos e os governantes.

\section{REFERÊNCIAS}

CÂMARA, Gilberto.; DAVIS, Clodoveu. Introdução ao Geoprocessamento. In: Câmara, G.; Davis, C.; Monteiro, A. M. V; Paiva, J. A.;D'alge, J. C. L. (Orgs.) Geoprocessamento: teoria e aplicações. São José dos Campos: Inpe, 2000. Disponível em <http://www.dpi.inpe.br/gilberto/livro>. 5p. Acesso em: 25 mar 2015.

NAÇÕES UNIDAS, Organização das. The Role Of Ict In The Proposed Urban Sustainable Development Goal And The New Urban Agenda. 2015 Disponível em

<http://www.ericsson.com/res/docs/2014/the-role-of-ict-in-the-new-urban-agenda.pdf>. Acesso em: 25 mar 2015.

FREITAS, Clarissa; GOMES, Viridiana; BORGES, Gabriel. Planejamento urbano com uso de sistema de informação geográfica: o caso de Feira de Santana, BA. Universitas: Arquitetura e Comunicação Social, 2013. V 10, № 1, p. 35-45.

PEREIRA, Danilo; SILVA, Gislane. As Tecnologias de Informação e Comunicação (TICs) como aliadas para o desenvolvimento. Cadernos de Ciências Sociais Aplicadas, 2010. Vitória da Conquista-BA. No 10. p. 151-174 
SABOYA, Renato. Análises Espaciais em Planejamento Urbano - Novas Tendências. Reurb Estudos Urbanos e Regionais, 2000. № 2. 2000. p. 61-79

TARDIN, Raquel. Espaços livres. Sistemas e Projeto Territorial. Rio de Janeiro: 7letras, 2008. 